\title{
Emodin sensitizes paclitaxel-resistant human ovarian cancer cells to paclitaxel-induced apoptosis in vitro
}

\author{
JUAN LI, PEISHU LIU, HONGLUAN MAO, ANCONG WANGA and XIAOLEI ZHANG \\ Department of Gynecology and Obstetrics, Qilu Hospital, Shandong University, \\ Wenhuaxi Road 107\#, Jinan, Shandong 250012, P.R. China
}

Received December 29, 2008; Accepted March 13, 2009

DOI: 10.3892/or_00000394

\begin{abstract}
Ovarian cancer has the highest mortality rate among gynecologic malignancies in the world, and the development of drug resistance is a major impediment toward successful treatment of the desease. Emodin has been reported to sensitize human tumor cells to chemotherapeutic agents. The present study investigated whether emodin could overcome chemoresistance of A2780/taxol cells. Cells were treated with different concentration of emodin alone or combined with paclitaxel, then the cell viability was measured by MTT and the apoptosis was determined by flow cytometric analysis. The changes of mRNA and protein were examined by QRT-PCR and Western blotting. The function of P-glycoprotein was also determined by flow cytometry. The results showed that emodin induced apoptosis alone at a high concentration and increased paclitaxel-induced apoptosis at a low concentration. It enhanced the sensitivity of A2780/taxol cells to paclitaxel with down-regulation of P-glycoprotein, XIAP and survivin. Taken together, the results demonstrated a dual role for emodin in the inhibition of drug resistant ovarian tumor growth by increasing paclitaxel cellular concentration and re-sensitizing the resistant cells to paclitaxel. Our results suggest the possibility of an innovative chemotherapeutic strategy that uses emodin in combination with paclitaxel to increase the sensitivity of tumor cells.
\end{abstract}

\section{Introduction}

Ovarian cancer has the highest mortality rate among gynecologic malignancies in the world (1). The standard treatment for ovarian cancer remains surgical debulking and chemotherapy with carboplatin and paclitaxel (2). However, the majority of ovarian cancer patients have one of the lowest 5 -year survival rates (3), and the development of drug resistance is a major impediment toward successful treatment

Correspondence to: Dr Peishu Liu, Department of Gynecology and Obstetrics, Qilu Hospital, Shandong University, Wenhuaxi Road 107\#, Jinan, Shandong 250012, P.R. China

E-mail: peishu_liu@yahoo.com.cn

Key words: emodin, paclitaxel, ovarian cancer, MDR-1, survivin, XIAP, apoptosis of the cancer (4). Thus, there have been a number of investigations aimed at understanding the mechanisms of drug resistance, so as to develop strategies to overcome the disease $(5,6)$.

Paclitaxel is an effective chemotherapeutic agent and widely used for the treatment of ovarian cancer, whereas the development of drug resistance limits its usefulness (2). To date, several mechanisms of paclitaxel resistance in ovarian cancer cells have been proposed, including overexpression of $\mathrm{ABC} / \mathrm{MDR}$ transporter family of proteins to increase the cellular efflux of paclitaxel, delayed G2/M transition, and alterations in apoptosis regulation (7-9).

As a traditional Chinese herbal medicine, emodin (1, 3, 8trihydroxy-6-methylanthr-aquinone) has been shown to possess a number of biological activities such as anti-bacterial (10), anti-inflammatory (11), immunosuppressive (12), and antitumor activity (13). Previous studies have demonstrated that emodin has anti-proliferative and anti-neoplastic effects in cancer cell lines. For example, emodin was shown to suppress the proliferation of Her-2/neu overexpressing lung cancer cells and sensitizes these cells to chemotherapeutic agents (14). Emodin has also been reported to sensitize different tumor cells to arsenic trioxide, including human esophageal carcinoma EC/CUHK1, human myeloid leukemic NB4, and acute myelocytic leukaemia (AML) U937 cells $(15,16)$. In our previous study, we found that emodin inhibits cell proliferation and induces apoptosis in ovarian cancer cell lines (data not shown), including the paclitaxel-resistant cell line A2780/taxol. Now we investigated whether emodin could sensitize paclitaxel-resistant tumor cells to paclitaxel cytotoxicity and its possible mechanisms.

\section{Materials and methods}

Chemicals and reagents. Emodin and paclitaxel were purchased from Sigma (USA) and were dissolved in dimethyl sulfoxide and ethanol, respectively. Antibodies against B-actin, P-gp, XIAP, survivin, caspase-3 were obtained from Santa Cruz.

Ovarian cancer cell lines. Paclitaxel-sensitive (A2780) and paclitaxel-resistant (A2780/taxol) human ovarian cancer cell lines were used. A2780 was obtained from China Center for Type Culture Collection (CCTCC), paclitaxel-resistant cell line A2780/taxol was obtained from Cancer Prevention and Treatment Research Institute of Guangxi Medical University 
Table I. Primers used for PCR.

\begin{tabular}{|c|c|c|c|c|}
\hline Survivin & $\begin{array}{l}\text { Antisense } \\
\text { Sense }\end{array}$ & $\begin{array}{l}\text { CAGATTTGAATCGCGGGACCC } \\
\text { CCAAGTCTGGCTCGTTCTCAG }\end{array}$ & 208 bp & NM_001168.2 \\
\hline XIAP & $\begin{array}{l}\text { Antisense } \\
\text { Sense }\end{array}$ & $\begin{array}{l}\text { CCGTGCGGTGCTTTAGTTGT } \\
\text { TTCCTCGGGTATATGGTGTCTGAT }\end{array}$ & 292 bp & NM_001167.2 \\
\hline MDR-1 & $\begin{array}{l}\text { Antisense } \\
\text { Sense }\end{array}$ & $\begin{array}{l}\text { CCCATCATTGCAATAGCAGG } \\
\text { GTTCAAACTTCTGCTCCTGA }\end{array}$ & $157 \mathrm{bp}$ & NM_000927.3 \\
\hline B-actin & $\begin{array}{l}\text { Antisense } \\
\text { Sense }\end{array}$ & $\begin{array}{l}\text { TGGCACCCAGCACAATGAA } \\
\text { CTAAGTCATAGTCCGCCTAGAAGCA }\end{array}$ & $188 \mathrm{bp}$ & NM_001101.2 \\
\hline
\end{tabular}

(17). Cells were grown in RPMI-1640 medium supplemented with $10 \%$ fetal bovine serum (FBS), $2 \%$ sodium pyruvate and $1 \%$ penicillin/streptomycin. Culture and drug-treatment of cells were carried out at $37^{\circ} \mathrm{C}$ in an atmosphere of $95 \%$ air $/ 5 \% \mathrm{CO}_{2}$. Cells were routinely trypsinized (0.05\% trypsin/ EDTA).

Cell viability assay. Cells were plated in 96-well plates at a density of 4000 cells per well. Cells were incubated overnight and then treated with different concentration of emodin or/and paclitaxol for $24 \mathrm{~h}$, respectively. All experiments were performed in triplicate and repeated at least three times. Emodin was dissolved in DMSO at a concentration of $100 \mathrm{mmol} / \mathrm{l}$ and added into the culture. To prevent crystallization, the plate was shaken well immediately after emodin was added. Paclitaxel was dissolved in ethanol at a concentration of $2 \mathrm{mmol} / \mathrm{l}$ for storage. The final DMSO concentration never exceeded $0.1 \%$, and this condition was used as the control in each experiment. At the end of incubation, the cells were washed with phosphate-buffered saline (PBS), and then $20 \mu \mathrm{l}$ of $5 \mathrm{mg} / \mathrm{ml}$ of MTT (Sigma) solution was subsequently added to each well with $180 \mu 1 \mathrm{RPMI}-$ 1640. After further incubation for $4 \mathrm{~h}$ at $37^{\circ} \mathrm{C}$, culture medium was removed and $150 \mu 1$ of DMSO was added to dissolve the resulting formazan crystals, and thoroughly mixed for $10 \mathrm{~min}$. The absorbance of samples was then measured by spectrometric absorbance at $570 \mathrm{~nm}$ with background subtraction at $630 \mathrm{~nm}$ on an automatic multiwell spectrophotometer (Bio-Rad-Coda, Richmond, CA).

Apoptosis analysis. Apoptotic rates were assessed with flow cytometry using the Annexin V-fluorescein isothiocyanate/ propidium iodide (PI) kit (Bipec Biopharma Corp, USA). Samples were washed with ice-cold PBS twice and resuspended in binding buffer at a density of $1 \times 10^{6}$ cells $/ \mathrm{ml}$. The cells were stained with Annexin V-FITC and gently votexed. After 15 min incubation at $4-8^{\circ} \mathrm{C}$ in the dark, PI was added to the cells for another 5 min incubation at $4-8^{\circ} \mathrm{C}$ in the dark. The results were analyzed by flow cytometry (FACScan, BD, USA). Annexin V-positive, PI-negative cells were scored as early apoptotic. Double-stained cells were considered as late apoptotic, and Annexin V-negative, PIpositive cells were considered as necrotic. The apoptosis rates estimated in the present study included all Annexin $\mathrm{V}$-positive populations.
Rhodamine 123(Rh123) efflux assay. Studies were carried out in A2780/taxol cells. Cells $\left(1 \times 10^{6}\right)$ were seeded in 6-well plates and cultured for $48 \mathrm{~h}$. A2780/taxol cells were pretreated with $10 \mu \mathrm{M}$ emodin or/and $1 \mu \mathrm{M}$ paclitaxel for $72 \mathrm{~h}$, respectively. After pretreatment, the cells were incubated with $200 \mathrm{ng} / \mathrm{ml} \mathrm{Rh} 123$ at $37^{\circ} \mathrm{C}$ for $60 \mathrm{~min}$ in the dark. After incubation, cells were washed twice with PBS, then the cells were incubated with RPMI- 1640 with $10 \%$ FBS at $37^{\circ} \mathrm{C}$ for $30 \mathrm{~min}$ and harvested for the measurement of Rh123 efflux. The sample was subjected to flow cytometry to measure the percentage of cells that did not emit fluorescence. All analyses were performed in triplicate in three separate experiments and the results are expressed as the mean percentage of the cells effluxing the dye, which reflects the efflux activity of P-glycoprotein (P-gp). The green fluorescence of Rh123 was excitated by $488 \mathrm{~nm}$ wavelength and measured by a $530 \mathrm{~nm}$ band-pass filter.

Quantitative reverse transcription and polymerase chain reaction $(Q R T-P C R)$ analyses. Total RNA was extracted from cells by the TRIzol reagent (Invitrogen, USA), according to the supplier's protocol. Total RNA ( $3 \mu \mathrm{g})$ samples were reverse transcribed to a final volume of $20 \mu 1$, using $50 \mathrm{pM}$ oligo(dT)-primer (Takara, Japan), 1 mM dNTP mix (Takara), $200 \mathrm{U}$ reverse transcriptase (Promega, USA), and $5 \mathrm{x}$ buffer $4 \mu 1$. RT reactions were performed on Mastercycler (Eppendorf, Germany).

QRT-PCR analysis was performed on Light Cycler (Roche Applied Science, USA) and on a volume of $20 \mu \mathrm{l}$ containing $1 \mu \mathrm{l}$ of cDNA, $10 \mu \mathrm{l}$ of x SYBR Green PCR Master Mix (Toyobo, Japan) $0.5 \mu 1$ of each primer (10 pM) and $8 \mu 1$ of DEPC-treated water. The sequences of the primers are shown in Table I.

The $20 \mu 1$ volume PCR reaction mixture was pre-heated at $95^{\circ} \mathrm{C}$ for $10 \mathrm{sec}$, followed by 45 cycles at $95^{\circ} \mathrm{C}$ for $5 \mathrm{sec}$, annealed for $10 \mathrm{sec}$ at $60^{\circ} \mathrm{C}$ (survivin and XIAP) $/ 55^{\circ} \mathrm{C}$ (MDR-1) and elongated for $10 \mathrm{sec}$ at $72^{\circ} \mathrm{C}$. The results were normalized to the relative amounts of $B$-actin.

Western blotting. Cells were washed twice with PBS and lysed in lysis buffer [50 mM Tris- $\mathrm{HCl}(\mathrm{pH} 8.0), 150 \mathrm{mM}$ $\mathrm{NaCl}, 0.5 \%$ Triton-X100, 2 mM EDTA (pH 8.0), $5 \mathrm{mM}$ DTT, $0.2 \mathrm{mM}$ phenylmethylsulfonyl fluoride, and $10 \mu \mathrm{g} / \mathrm{ml}$ aprotinin] on ice for $20 \mathrm{~min}$. The lysates were centrifuged at $12000 \mathrm{~g}$ at $4^{\circ} \mathrm{C}$ for $10 \mathrm{~min}$, and the protein concentrations of 

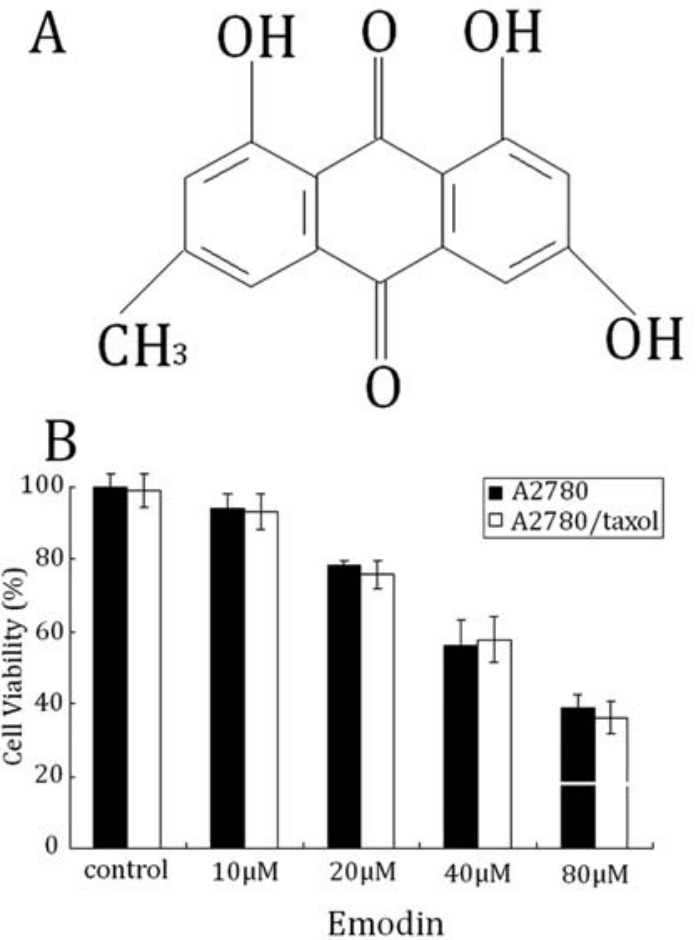

Figure 1. Effect of emodin on cell viability. (A) Molecular structure of emodin (1,3,8-trihydroxy-6-methylanthraquinone). (B). The effect of emodin on growth of A2780 and A2780/taxol cell lines. Cells were incubated with different concentration of emodin for $24 \mathrm{~h}$. Cell viability was assessed by MTT assay. Emodin $(10 \mu \mathrm{M})$ treated cells displayed no significant growth inhibition as compared to that of control treated group ( $\mathrm{P}>0.05$ for both cell lines), but $80 \mu \mathrm{M}$ of emodin showed significant growth inhibition in both cell lines $(\mathrm{P}<0.01)$. Data represent mean $\pm \mathrm{SD}$ of triplicates, similar results were obtained in three independent experiments.

the supernatants were determined using the BCA method. For Western blot analysis, equal amounts of total protein were loaded onto 8 or $10 \%$ SDS-polyacrylamide gels and the proteins electrophoretically transferred onto nitrocellulose membranes. The membranes were blocked in 5\% non-fat milk in Tris-buffered saline with $0.05 \%$ Tween-20 (TBST) for $2 \mathrm{~h}$ at $37^{\circ} \mathrm{C}$, and then incubated with an anti-XIAP, antisurvivin, anti-P-gp, anti-caspase 3 or anti-ß-actin primary antibody overnight at $4^{\circ} \mathrm{C}$, respectively. Horseradish peroxidase (HRP)-conjugated secondary antibody was added for $2 \mathrm{~h}$ at room temperature. Detection was performed by enhanced chemiluminescence (ECL, Pierce, USA).

Statistical analysis. Data were expressed as means $\pm \mathrm{SD}$, and analyzed by the Student's t-test on SPSS 11.0. P-values below 0.05 were regarded as statistically significant.

\section{Results}

Emodin inhibits the viability of ovarian cancer cells. The chemical structure of emodin is shown in Fig. 1A. To determine the effect of emodin on ovarian cancer cell viability alone, we treated ovarian cancer cell lines A2780 and A2780/ taxol with different concentrations $(10,20,40$ and $80 \mu \mathrm{M})$ of emodin for $24 \mathrm{~h}$. Cell viability was measured by MTT assay. As shown in Fig. 1B, a dose-dependent decrease of cell viability was observed in both cases. cells treated with $10 \mu \mathrm{M}$ of emodin displayed no significant growth inhibition as
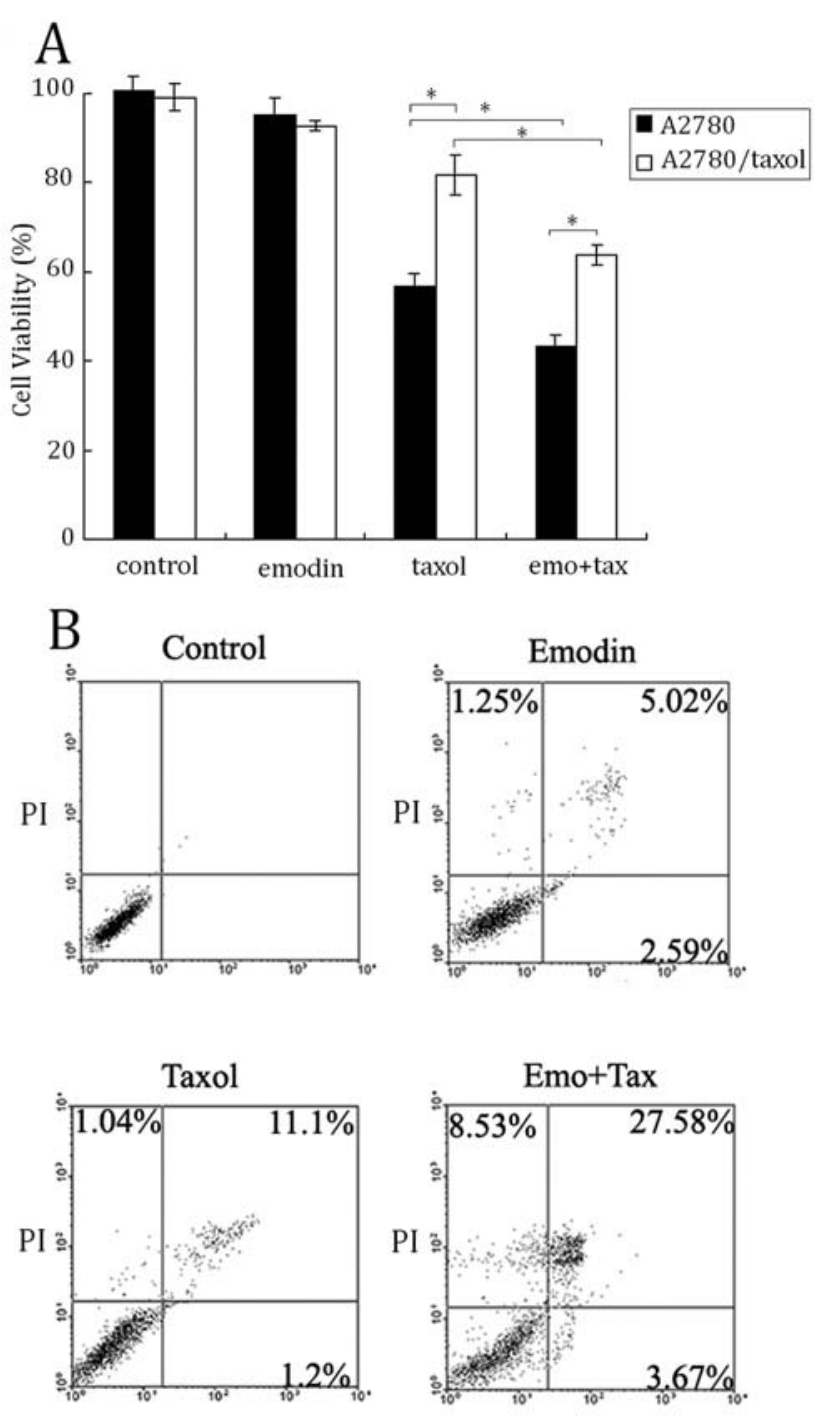

\section{AnnexinV -FITC}

Figure 2. Effect of emodin and/or paclitaxel on the viability of A2780 and A2780/taxol cell lines. Cells were incubated with $10 \mu \mathrm{M}$ of emodin and $1 \mu \mathrm{M}$ of paclitaxel for $24 \mathrm{~h}$. (A) Cell viability was evaluated using MTT assay. (B) Apoptotic rate of A2780/taxol cells treated for $24 \mathrm{~h}$. Density plots of flow cytometry. The experiment were repeated three times.

compared to control treated cells $(0.1 \%$ DMSO) $(\mathrm{P}>0.05$ for both cell lines), but $80 \mu \mathrm{M}$ of emodin showed significant growth inhibition in both cell lines $(\mathrm{P}<0.01)$. The cytotoxic effect of emodin against paclitaxel-sensitive and -resistant ovarian cancer cells shows no significant difference in each group. This result indicates the anticancer potential of emodin is not inhibited in paclitaxel-resistant cells.

Low concentration of emodin enhances the cytotoxicity of paclitaxel in resistant ovarian cancer cell lines. To investigate the possibility that emodin enhance the cytotoxicity of paclitaxel, we examined the combined effects of emodin and paclitaxel in both paclitaxel sensitive and resistant ovarian cancer cells. Cells were treated with low concentration of emodin $(10 \mu \mathrm{M})$, paclitaxel $(1 \mu \mathrm{M})$, or combined for $24 \mathrm{~h}$, respectively. Cytotoxicity was assessed using MTT viability assay. The results (Fig. 2A) indicated that $10 \mu \mathrm{M}$ emodin alone showed no significant growth inhibition as compared 
A

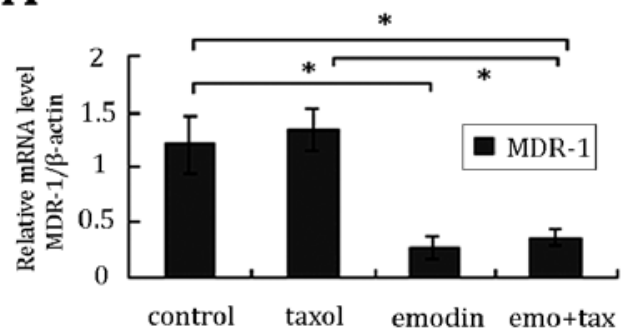

C

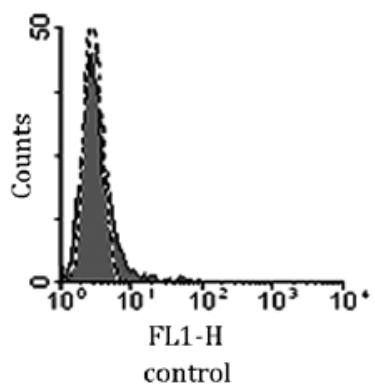

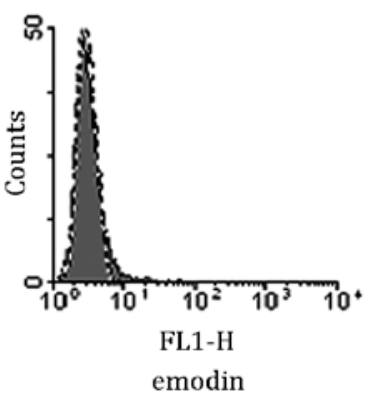

B

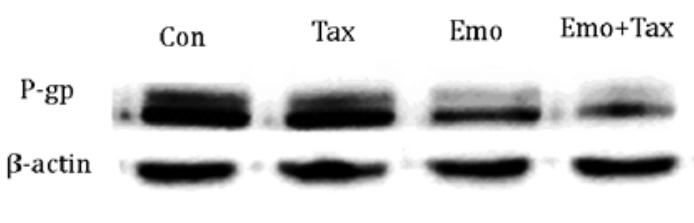

Figure 3. Effect of emodin on P-gp expression and function in A2780/taxol cells. Cells were pretreated with $10 \mu \mathrm{M}$ of emodin or/and $1 \mu \mathrm{M}$ paclitaxel for $24 \mathrm{~h}$. (A) The total RNA was detected as described before. As shown in (A), there was a significantly decrease of MDR-1 mRNA expression in cells treated with emodin alone or combined with paclitaxel $(\mathrm{P}<0.01)$. (B) The expression of P-gp was detected by Western blotting with mouse anti-human monoclonal antibody against P-gp. The expression of P-gp was attenuated with treatment of emodin or combined with paclitaxel. (C) After cultured with emodin or paclitaxel, the cells were treated and analysed as described before. A2780/taxol cells in the absence of emodin exhibited a significant decrease of Rh123 compared to A2780 cells, while a notable increase was seen in A2780/taxol cells in the presence of emodin (10 $\mu \mathrm{M})$.

with that of control group ( $\mathrm{P}>0.05$ for both cell lines). Treatment of A2780 cells with paclitaxel or combined with emodin inhibited cell viability by 44 and $57 \%$, respectively $(\mathrm{P}<0.01)$. In A2780/taxol cells, the results also showed a significant inhibition of cell growth by paclitaxel $(18 \%)$ alone or combined with emodin $(36 \%)(\mathrm{P}<0.01)$. The effect of paclitaxel is lower in resistant cells compared with sensitive cells $(\mathrm{P}<0.01)$. The results of flow cytometry showed that emodin at $10 \mu \mathrm{M}$ facilitated paclitaxel-induced apoptosis, but it had little cytotoxicity when used alone at this low concentration (Fig. 2B).

Emodin down-regulates MDR-1 expression and function. We found that emodin enhanced paclitaxel cytotoxicity in paclitxel-resistant cells, so we investigated further to find the possible mechanisms. Expression of MDR-1 was first investigated. The result of QRT-PCR showed that the gene expression of MDR-1 was significantly attenuated when the cells were treated with emodin alone or combination with paclitaxel $(\mathrm{P}<0.01)$, whereas no change was seen with paclitaxel alone $(\mathrm{P}>0.05)$ (Fig. $3 \mathrm{~A})$. These results were also confirmed by Western blot analysis (Fig. 3B).

Rhodamine 123 is a well-established P-gp substrate. The activity of the P-gp drug pump can be gauged by the degree of intracellular efflux of rhodamine 123 , which can in turn be determined by the measurement of intracellular fluorescence. In this assay, we further investigated the effect of emodin on the P-gp activity by detecting efflux of Rh123 in A2780/taxol cells (Fig. 3C). Cells treated with emodin at the concentrations of $10 \mu \mathrm{M}$ significantly decreased the efflux of Rh123 $(\mathrm{P}<0.01)$
Table II. Rh123 efflux assay.

\begin{tabular}{lc}
\hline Group & Efflux activity (\%) \\
\hline Control & 100 \\
Taxol & $106.24 \pm 3.2$ \\
Emodin & $32.11 \pm 8.8^{\mathrm{a}}$ \\
Emodin+Taxol & $39.24 \pm 5.9^{\mathrm{a}}$ \\
\hline
\end{tabular}

${ }^{a} \mathrm{P}<0.01$ compared with the control group MDR1-mediated rhodamine efflux assay as measured by flow cytometry. Cultured for $72 \mathrm{~h}$, they were treated with $200 \mathrm{ng} / \mathrm{ml} \mathrm{Rh} 123$ for $1 \mathrm{~h}$ as described. The value of efflux activity of A2780/taxol cells treated with $0.1 \%$ DMSO was set at $100 \%$. Results show the mean \pm SD of three independent experiments.

(Table II). Emodin induced the increase of Rh123 in A2780/ taxol cells, suggesting that emodin had the ability to inhibit the drug-transport activity of P-gp, which is a major reason for inducing elevation of intracellular accumulation of paclitaxel in A2780/taxol cells.

Emodin reduces the expression of anti-apoptotic molecules. The cells were co-treated with emodin and paclitaxel for $72 \mathrm{~h}$, then the levels of survivin and XIAP were detected by QRTPCR and Western blotting. As shown in Fig. 4A, we found when co-treated with emodin, the expression of XIAP and 

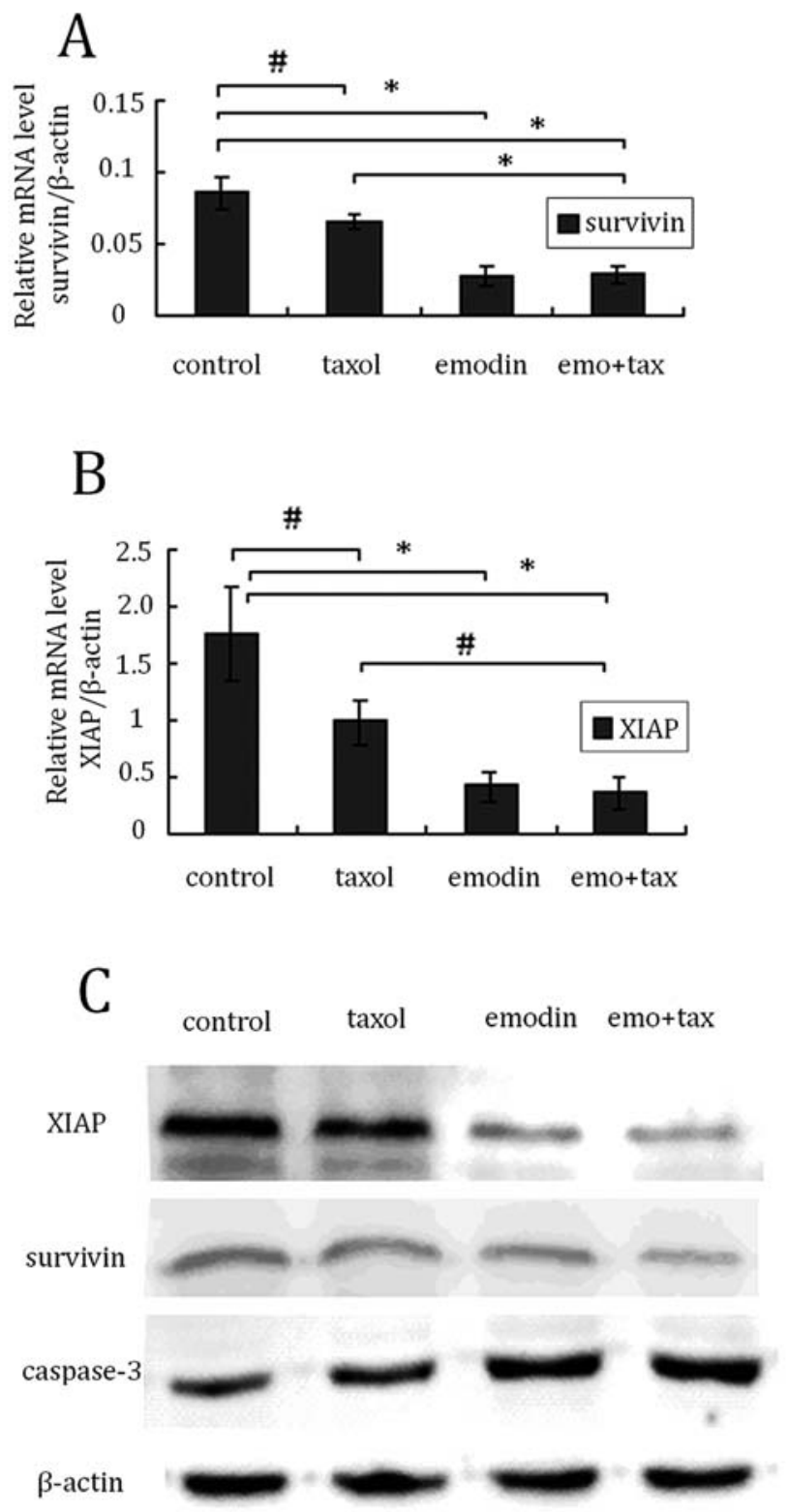

Figure 4. Effect of emodin on anti-apoptotic molecule expression in A2780/ taxol cells. QRT-PCR showed transcript expression of survivin (A) and XIAP (B) was decreased in cells treated with emodin alone or combined with paclitaxel $(\mathrm{P}<0.01$ and $<0.05$, respectively). The expression of XIAP and survivin protein were detected by Western blotting. The expressions of XIAP and survivin were reduced with treatment of emodin or combined with paclitaxel. Furthermore, the expressions of cleaved fragments of caspase-3 were significantly enhanced $(\mathrm{C}) .\left({ }^{*} \mathrm{P}<0.01,{ }^{\#} \mathrm{P}<0.05\right)$.

survivin was decreased compared to treatment with paclitaxel alone (Fig. 4A and B). Furthermore, treatment with emodin enhanced the activation of caspase- 3 as evidenced by significantly enhancing expression of cleaved fragments of caspase-3.

\section{Discussion}

Drug resistance is the main cause of treatment failure and mortality in cancer patients. Paclitaxel is a widely used chemotherapeutic agent against a number of malignancies, including ovarian cancer (18). However, development of drug-resistance following prolonged treatment or upon relapse of the disease is an undesirable effect (19). Previous studies have suggested several possible reasons for paclitaxel resistance, including increased drug cellular efflux by overexpressed P-gp encoded by multidrug resistance gene-1 (MDR-1) and deregulated expression of anti-apoptotic or proapoptotic molecules $(20,21)$.

Emodin has been reported to possess anticancer effect on several human cancers in vitro $(22,23)$. It has also been proved to enhance cytotoxic effects of chemotherapeutic agents in different cancer cells $(14,15)$. The treatment of cancer cells with emodin alone or in combination with other chemotherapeutic agents has been shown to effectively counteract tumor progression, although the emodin-mediated molecular mechanism responsible for this effect remains to be fully elucidated.

Our report described that emodin inhibits cell proliferation in ovarian cancer cells A2780 and A2780/taxol, and the anticancer activity is based on apoptotic cell death. The cytotoxic effect of emodin against paclitaxel sensitive and resistant cells showed no significant difference, while comparable to that of paclitaxel under the conditions used; its effect was significantly higher in the resistant cells. This indicated that the anticancer potential of emodin was not inhibited in paclitaxel-resistant cells. The substantially higher cytotoxicity induced by the co-administration of emodin and paclitaxel seemed to suggest a possible synergistic effect. Therefore, we tried to find the possible mechanisms with further research.

MDR-1 encodes a 170-kDa transmembrane protein P-gp. P-gp functions as an efflux pump to decrease the intracellular accumulation of a variety of lipophilic drugs, including paclitaxel (25). Previous studies showed that P-gp contributed to paclitaxel resistance and MDR-1 gene expression might be a useful predictor for combination paclitaxel based chemotherapy in ovarian cancer cells (26). Cellular P-gp can be detected in protein levels by Western blot analysis with monoclonal antibodies against human P-gp. Its function is also evaluated by measuring Rh123 efflux from cells. Rh123 is a special substrate for P-gp. The uptake of Rh123 results from passive inward diffusion (27), while the efflux is known to be P-gp-dependent. Rh123 has been used extensively as an indicator of P-gp activity in drug-resistant cell lines with P-gp overexpression (28).

Paclitaxel-resistant cell line A2780/taxol was generated from cell line A2780 through exposure to increasing sublethal concentrations of paclitaxel (17). Analysis of cellular protein expression demonstrated the highly elevated expression of survivin, XIAP and P-gp, compared with its parental cell line A2780 (29). In our study, we found emodin has a dual function of inhibiting the P-gp drug-pump and expression. The reversal effect of emodin on paclitaxel-resistance of A2780/taxol cells might be via down-regulating P-gp.

Successful treatment with chemotherapeutic agents is largely dependent on their ability to trigger cell death in tumor cells; therefore, trying to decrease the overexpression of anti-apoptotic molecules may affect the proximal level of apoptotic threshold. As direct caspase inhibitors and participants in a variety of survival signaling pathways, the inhibitor of apoptosis protein (IAP) family are important to the control of cell proliferation and drug resistance in multiple cancer 
types (30). As the important IAPs members, XIAP (X-linked inhibitor of apoptosis) and survivin are up-regulated in most human tumor cells and make the cancer cells escape from apoptosis. Evidence indicates that survivin and XIAP are associated with chemoresistance and decrease of these IAPs induced apoptosis in chemoresistant human ovarian cancer cells $(31,32)$. In the present study, we have investi-gated the regulation and role of two anti-apoptotic factors, survivin and $\mathrm{XIAP}$, in ovarian cancer cells, and tried to explain their relationship with cellular resistance to paclitaxel. We found emodin could increase the apoptosis induced by paclitaxel, and the expression of XIAP and survivin were reduced. Treatment with emodin enhanced the activation of caspase- 3 . It was suggested that emodin could down-regulate the expression of anti-apoptotic protein, survivin, in esophageal carcinoma cell line EC/CUHK1 (24), coinciding with our results. The enhanced apoptosis by emodin and paclitaxel may be partly due to the reduction of XIAP and survivin.

Collectively, we demonstrated for the first time that emodin induced apoptosis of ovarian cancer cells and enhanced the sensitivity of A2780/taxol cells to paclitaxel. The results demonstrated that emodin could induce apoptosis of resistant ovarian cancer cells by increasing the cellular concentration of paclitaxel and decreasing the expression of anti-apoptotic molecules. The substantially higher cytotoxicity induced by the co-administration of emodin and paclitaxel seems to suggest a possible synergistic effect presumably due to emodin-mediated reduction of the expression of P-gp, XIAP and survivin.

\section{References}

1. Puiffe ML, Le Page C, Filali-Mouhim A, et al: Characterization of ovarian cancer ascites on cell invasion, proliferation, spheroid formation, and gene expression in an in vitro model of epithelial ovarian cancer. Neoplasia 9: 820-829, 2007.

2. Matei D: Novel agents in ovarian cancer. Expert Opin Investig Drugs 16: 1227-1239, 2007.

3. Jemal A, Murray T, Ward E, et al: Cancer statistics, 2005. CA Cancer J Clin 55: 10-30, 2005.

4. Harries M and Gore M: Part II: chemotherapy for epithelial ovarian cancer-treatment of recurrent disease. Lancet Oncol 3: 537-545, 2002.

5. Kartalou M and Essigmann JM: Mechanisms of resistance to cisplatin. Mutat Res 478: 23-43, 2001.

6. Agarwal R and Kaye SB: Ovarian cancer: strategies for overcoming resistance to chemotherapy. Nat Rev Cancer 3: 502-516, 2003.

7. Peer D, Dekel Y, Melikhov D and Margalit R: Fluoxetine inhibits multidrug resistance extrusion pumps and enhances responses to chemotherapy in syngeneic and in human xenograft mouse tumor models. Cancer Res 64: 7562-7569, 2004.

8. Huang Y, Ray S, Reed JC, Ibrado AM, Tang C, Nawabi A and Bhalla K: Estrogen increases intracellular p26Bcl-2 to p21Bax ratios and inhibits taxol-induced apoptosis of human breast cancer MCF-7 cells. Breast Cancer Res Treat 42: 73-81, 1997.

9. Tan M, Jing T, Lan KH, et al: Phosphorylation on tyrosine-15 of p34(Cdc2) by ErbB2 inhibits p34(Cdc2) activation and is involved in resistance to taxol-induced apoptosis. Mol Cell 9: 993-1004, 2002.

10. Basu S, Ghosh A and Hazra B: Evaluation of the antibacterial activity of Ventilago madraspatana Gaertn., Rubia cordifolia Linn. and Lantana camara Linn.: isolation of emodin and physcion as active antibacterial agents. Phytother Res 19: 888-894, 2005 .
11. Kitano A, Saika S, Yamanaka O, Ikeda K, Okada Y, Shirai K and Reinach PS: Emodin suppression of ocular surface inflammatory reaction. Invest Ophthalmol Vis Sci 48: 5013-5022, 2007.

12. Kuo YC, Tsai WJ, Meng HC, Chen WP, Yang LY and Lin CY: Immune reponses in human mesangial cells regulated by emodin from Polygonum hypoleucum Ohwi. Life Sci 68: 1271-1286, 2001.

13. Wang XD, Gu LQ and Wu JY: Apoptosis-inducing activity of new pyrazole emodin derivatives in human hepatocellular carcinoma HepG2 cells. Biol Pharm Bull 30: 1113-1116, 2007.

14. Zhang L and Hung MC: Sensitization of HER-2/neu-overexpressing non-small cell lung cancer cells to chemotherapeutic drugs by tyrosine kinase inhibitor emodin. Oncogene 12: 571-576, 1996.

15. Yang J, Li H, ChenYY, et al: Anthraquinones sensitize tumor cells to arsenic cytotoxicity in vitro and in vivo via reactive oxygen species-mediated dual regulation of apoptosis. Free Radic Biol Med 37: 2027-2041, 2004.

16. Yi J, Yang J, He R, Gao F, Sang H, Tang X and Ye RD: Emodin enhances arsenic trioxide-induced apoptosis via generation of reactive oxygen species and inhibition of survival signaling. Cancer Res 64: 108-116, 2004.

17. Li L, Luan Y, Wang G, et al: Development and characterization of five cell models for chemoresistance studies of human ovarian carcinoma. Int J Mol Med 14: 257-264, 2004.

18. Marupudi NI, Han JE, Li KW, Renard VM, Tyler BM and Brem H: Paclitaxel: a review of adverse toxicities and novel delivery strategies. Expert Opin Drug Saf 6: 609-621, 2007.

19. Harries M and Gore M: Part I: chemotherapy for epithelial ovarian cancer-treatment at first diagnosis. Lancet Oncol 3: 529-536, 2002.

20. Lowe SW and Lin AW: Apoptosis in cancer. Carcinogenesis 21: 485-495, 2000.

21. Goyal L: Cell death inhibition: keeping caspases in check. Cell 104: 805-808, 2001.

22. Kim HR, Kim K, Lee KH, Kim SJ and Kim J: Inhibition of casein kinase 2 enhances the death ligand- and natural killer cell-induced hepatocellular carcinoma cell death. Clin Exp Immunol 152: 336-344, 2008.

23. Cha TL, Qiu L, Chen CT, Wen Y and Hung MC: Emodin down-regulates androgen receptor and inhibits prostate cancer cell growth. Cancer Res 65: 2287-2295, 2005.

24. Zhang L, Lau YK, Xia W, Hortobagyi GN and Hung MC: Tyrosine kinase inhibitor emodin suppresses growth of HER-2/ neu-overexpressing breast cancer cells in athymic mice and sensitizes these cells to the inhibitory effect of paclitaxel. Clin Cancer Res 5: 343-353, 1999.

25. Ozben T: Mechanisms and strategies to overcome multiple drug resistance in cancer. FEBS Lett 580: 2903-2909, 2006.

26. Kamazawa S, Kigawa J, Kanamori Y, Itamochi H, Sato S, Iba T and Terakawa N: Multidrug resistance gene-1 is a useful predictor of paclitaxel-based chemotherapy for patients with ovarian cancer. Gynecol Oncol 86: 171-176, 2002.

27. Krishna R and Mayer LD: Multidrug resistance (MDR) in cancer. Mechanisms, reversal using modulators of MDR and the role of MDR modulators in influencing the pharmacokinetics of anticancer drugs. Eur J Pharm Sci 11: 265-283, 2000.

28. Galski H, Sivan H, Lazarovici P and Nagler A: In vitro and in vivo reversal of MDR1-mediated multidrug resistance by KT-5720: implications on hematological malignancies. Leuk Res 30: 1151-1158, 2006.

29. Zhou L, Liu P, Chen B, et al: Silibinin restores paclitaxel sensitivity to paclitaxel-resistant human ovarian carcinoma cells. Anticancer Res 28: 1119-1127, 2008.

30. Lopes RB, Gangeswaran R, McNeish IA, Wang Y and Lemoine NR: Expression of the IAP protein family is dysregulated in pancreatic cancer cells and is important for resistance to chemotherapy. Int J Cancer 120: 2344-2352, 2007.

31. Caldas H, Jaynes FO, Boyer MW, Hammond S and Altura RA: Survivin and Granzyme B-induced apoptosis, a novel anticancer therapy. Mol Cancer Ther 5: 693-703, 2006.

32. Gagnon V, van Themsche C, Turner S, Leblanc V and Asselin E: Akt and XIAP regulate the sensitivity of human uterine cancer cells to cisplatin, doxorubicin and taxol. Apoptosis 13: 259-271, 2008. 